\title{
HISTORIA
}

\section{Pedro José Martínez Moreno.Practicante de la Armada: algo más que un personaje}

\section{Pedro José Martínez Moreno, a Navy Practitioner: more than just a personage Pedro José Martínez Moreno. Practitioner da armada: mais que uma simples personagem}

\section{Manuel Cano Leal ${ }^{1}$ \& Mariana García González².}

${ }^{1}$ Miembro del Grupo de Investigación de Historia de la Enfermería Gaditana del Excmo. Colegio de Enfermería de Cádiz. Orcid: 0000-0002-3585-313X. Correo electrónico: manuelcl3@hotmail.com ${ }^{2}$ Miembro del Grupo de Investigación de Historia de la Enfermería Gaditana del Excmo. Colegio de Enfermería de Cádiz. Orcid: 0000-0003-4922-9204. Correo electrónico: cordo_besa@hotmail.com

Correspondencia: Excmo. Colegio Oficial de Enfermería de Cádiz. C/José del Toro, 11 1, 11004, Cádiz Correo electrónico de contacto: manuelcl3@hotmail.com

Cómo citar este artículo: Cano Leal, M., \& García González, M. (2021) Pedro José Martínez Moreno. Practicante de la Armada: algo más que un personaje. Cultura de los Cuidados (Edición digital), 25(59). Recuperado de http://dx.doi.org/10.14198/cuid.2021.59.08

Recibido:04/11/2020 Aceptado: 12/01/2021 


\section{RESUMEN}

Los Practicantes de la Armada, desde principios de siglo XX hasta finalizar la guerra civil, en las distintas zonas marítimas de nuestra geografía, fueron protagonistas destacados de la institución colegial. Eran profesionales muy bien formados $\mathrm{y}$ con amplias competencias laborales, gran bagaje de vivencias y con un elevado sentido del corporativismo como arma para defender unos derechos que no les eran reconocidos. El objetivo de este estudio consiste en describir la vida de Pedro J. Martínez desde la doble perspectiva de militar y practicante. Para ello, hemos empleado una metodología basada en el proceso heurístico de fuentes primarias de origen archivístico localizadas en el Archivo Central del Cuartel General de la Armada y Archivo del Colegio de Enfermería de Cádiz. También hemos obtenido importante información de la prensa profesional del momento, como es el caso de El Practicante Gaditano y recurrido a la documentación personal con la Catedrática Victoria Fernández Díaz. Toda la documentación obtenida ha sido analizada siguiendo las orientaciones de la disciplina histórica, especialmente la biográfica y de vida. Los resultados obtenidos en esta investigación nos llevan a perfilar a Martínez Moreno como un individuo que, por sus cualidades y conocimientos, destacaba en su actividad profesional y en el ambiente social. Cartagenero de nacimiento y practicante de la Armada, era algo más que un personaje. Desde su tierra natal, donde fue presidente del Colegio Departamental de Cartagena, fundador y propietario de la revista "El Practicante Moderno", hasta llegar a la capital gaditana donde resultó elegido presidente del Colegio de Practicantes de Cádiz. No pasaba nunca desapercibido y destacaba en todos los ámbitos donde residía. También era un profesional militar muy considerado por sus superiores y así le era oficialmente reconocido. En cumplimiento al Decreto del Gobierno provisional de la República de 23 de abril de 1931, prestó la preceptiva promesa de adhesión y fidelidad a la República. Esa lealtad, le costaría salir exiliado al finalizar la guerra civil, y morir años después, en tierra extranjera (Túnez), sin el reconocimiento debido y el mayor de los olvidos. Por tanto, las conclusiones extraídas de nuestro trabajo son que la vida de Pedro José Martínez Moreno se desarrolló de forma especialmente relevante tanto desde la perspectiva militar como sanitaria, dado que los diferentes cargos en las presidencias colegiales denotan unas habilidades sociales y profesionales altamente infrecuentes, del mismo modo que denotan su continuo y profundo compromiso con la profesión de enfermería desde la representatividad colegial.

Palabras clave: practicante armada; colegios practicantes; guerra civil.

\section{ABSTRACT}

The Navy Surgery Practitioners, from the beginning of the twentieth century until the civil war, the different maritime of our geography, they were prominent protagonist of the collegiate institution. They were very well trained professionals with extensive work skills, great baggage of experiences and with a high sense of corporatism as a weapon to defend rights that were not recognized to them. The objective of this study is describing the life of Pedro J. Martínez Moreno from the dual perspective of military and surgery practitioner. To do this, we have used a methodology based on the heuristic process of primary sources of archival origin located in the Central Archive of the Headquarters of the Navy and file of the College of Nursing of Cádiz. We have also obtained important information from the professional press of the moment, as is the El Practicante Gaditano and resorted to personal documentation with Professor Victoria Fernández Díaz. All the documentation obtained has been analyzed according to the orientation of historical discipline, especially biographical and life. The results obtained in this research lead us to profile Martínez Moreno as an individual who, for his qualities and knowledge, he exceled in 
his professional activity and in the social environment. Cartagenero by birth and navy surgery practitioner, was more than just a character. From his homeland, where he was president of the Departmental College of Cartagena, founder and owner of the professional magazine "El Practicante Moderno", until arriving in the capital of Cádiz where he was elected president of College of Surgery Practitioners of Cádiz. It never went unnoticed and stood out in all areas where he resided. He was also a military professional highly regarded by his superiors and thus was officially recognized. In compliance with the Decree of the Provisional Government of the Republic of 23 April 1931, it provided the mandatory promise of accession and fidelity to the Republic. That loyalty would cost him to go into exile at the end of the civil war, and die years later, in a foreign land (Tunisia), without due recognition and the greatest oblivion. Therefore, the conclusions drawn from our work are that the life of Pedro José Martínez Moreno developed in an especially relevant way from both the military and health perspective, given that the different positions in the collegiate presidencies denote highly infrequent social and professional skills, in the same way that they denote their continuous and deep commitment to the nursing profession from collegiate representation.

Keywords: Navy surgery practitioner, surgery practitioner College, civil war.

\section{RESUMO}

Os Praticantes da Marinha, desde o início do século $\mathrm{XX}$ até ao fim da guerra civil, nas diferentes áreas marítimas da nossa geografia, foram protagonistas notáveis da instituição colegial. Eram profissionais muito bem treinados, com vastas competências de trabalho, uma grande experiência e um forte sentido de corporativismo como arma para defender direitos que não eram reconhecidos. $\mathrm{O}$ objectivo deste estudo é descrever a vida de Pedro J. Martínez a partir da dupla perspectiva de militar e praticante. Para tal, utilizámos uma metodologia baseada no processo heurístico de fontes primárias de origem arquivística localizadas no Arquivo Central do Quartel-General da Marinha e no Arquivo do Colégio de Enfermagem de Cádis. Obtivemos também informações importantes da imprensa profissional da época, como é o caso de El Practicante Gaditano e recorremos à documentação pessoal com a Professora Victoria Fernández Díaz. Toda a documentação obtida foi analisada seguindo as directrizes da disciplina histórica, especialmente a biografia e a história de vida. Os resultados obtidos nesta investigação levam-nos a traçar o perfil de Martínez Moreno como um indivíduo que, devido às suas qualidades e conhecimentos, se destacou na sua actividade profissional e no meio social. Cartaginês de nascimento e estagiário da Marinha, ele era mais do que uma personagem. Desde a sua pátria, onde foi presidente do Colégio Departamental de Cartagena, fundador e proprietário da revista "El Practicante Moderno", até à capital de Cádis, onde foi eleito presidente do Colégio de Praticantes de Cádis. Ele nunca passou despercebido e destacou-se em todas as áreas onde viveu. Era também um profissional militar altamente considerado pelos seus superiores e foi oficialmente reconhecido como tal. Em conformidade com o Decreto do Governo Provisório da República de 23 de Abril de 1931, fez a promessa obrigatória de adesão e lealdade à República. Esta lealdade custar-lhe-ia ir para o exílio no final da guerra civil, e morrer anos mais tarde, numa terra estrangeira (Tunísia), sem o devido reconhecimento e o maior esquecimento. Portanto, as conclusões retiradas do nosso trabalho são que a vida de Pedro José Martínez Moreno se desenvolveu de uma forma particularmente relevante tanto do ponto de vista militar como do ponto de vista da saúde, uma vez que as diferentes posições nas presidências colegiadas denotam competências sociais e profissionais altamente invulgares, da mesma forma que denotam o seu compromisso contínuo e profundo com a profissão de enfermagem a partir da representatividade colegial.

Palavras-chave: praticante armado, colégios de praticantes, guerra civil. 


\section{INTRODUCCION}

Los practicantes de la Armada en el último tercio del siglo XIX y primero del $\mathrm{XX}$, soportaron situaciones extremas en el ámbito profesional, guerras coloniales, la guerra de África, etc. Todo ello aderezado con las vivencias propias de los navegantes. Conocimiento de otras culturas, cambios de destinos y por tanto de zonas geográficas diferentes, todo ello les proporcionaba una marcada personalidad y un enriquecimiento cultural y humanístico. Sin desmerecer para nada otros ámbitos laborales, en unos tiempos donde sobrevivir era una odisea, el practicante de la Marina destacaba en ciertos círculos, de una manera ostensible.

En el primer tercio del siglo XX, cinco de sus miembros presidieron la institución colegial gaditana, incluido su fundador y primer presidente José Núñez Ramírez. Si a todo ello, sumamos unas habilidades personales innatas, don de gente, presencia física, etc. donde nuestro personaje destacaba sobre sus propios compañeros, se puede concebir mejor esta biografía.

Mucho se ha escrito sobre la Sanidad militar española y sus protagonistas, médicos y practicantes, desde Clavijo y Clavijo S. (1925) Gracia Rivas, M. (1995) hasta de la Enfermería en la Defensa por González Yanes, J. (2014). Pero no son tantos los que han abordado su estudio desde la investigación biográfica, desde la relevancia colegial, aunque en los últimos años han estado motivados numerosos trabajos sobre biografías reflejados en los libros editados de los Congresos Nacionales de Historia de la Enfermería, que han sido apoyados por los Colegios Profesionales, proporcionando interesantes e inéditos trabajos sobre la historia de las instituciones colegiales.

Sin embargo, este Grupo de Investigación desde sus comienzos ha puesto verdadero interés en desarrollar el género biográfico de los protagonistas en la historia del Colegio de Cádiz, como la de Manuel Quignon Lubrano (Enfermería Gaditana, 2018), Julio Cabilla Alberto (Cuadernos de Investigación de Fondos del Archivo UCA, 2019) y el Reconocimiento a las Presidentas de los Colegios de Auxiliares Sanitarios de
Cádiz, Sección Enfermeras y Matronas (2018). A lo que podemos añadir el proceso de documentación para la realización de las cartelas biográficas correspondientes a los retratos que se encuentran en la Galería de Presidentes y Presidentas del Colegio de Cádiz.

Estas investigaciones, así como la que se recoge en este trabajo han sido llevadas a cabo mediante un proceso heurístico basado en la búsqueda de fuentes documentales, recogidos fundamentalmente en el Archivo Central del Cuartel General de la Armada y del Viso (expedientes militares), el Archivo del Colegio de Enfermería de Cádiz (expediente colegial) y recursos electrónicos como las consultas del Diario Oficial del Ministerio de Marina. También ha sido fundamental la contribución de la Catedrática Victoria Fernández Díaz, mediante entrevista oral y aportación de documentos de sus propias investigaciones que nos ha completado el recorrido profesional y personal de Pedro J. Martínez. Hemos de señalar El Practicante Gaditano, revista profesional colegial (19161939) como una fuente primordial para la obtención de datos, ya que fue su Director durante dos años.

\section{DESARROLLO DEL TEMA}

Pedro J. Martínez Moreno nace en Cartagena (Murcia) el seis de abril de 1889. Hijo de José y de Lucía. Estudia la carrera de Practicante en la Facultad de Medicina de la Universidad Central en Madrid, finalizándola con 17 años, en 1906. Recién finalizado los estudios, ingresa en la Cruz Roja como socio y en calidad de Practicante. A partir de este momento comienza una vida personal, profesional e institucional, tan intensa y peculiar, que difícilmente podremos encontrar alguien semejante. En 1907 fue nombrado practicante de la Sociedad de Seguros de Accidentes de Trabajo "La Alianza" y comenzó a trabajar como supernumerario de la Beneficencia Municipal de Cartagena.

Durante la Guerra del Rif, también llamada segunda Guerra de Marruecos en 1909, prestó relevantes servicios en la Cruz Roja, en la conducción de soldados heridos desde Melilla al Hospital de Marina de Cartagena, hecho por el que fue 
condecorado. Siendo esta circunstancia quizás, la que le animó a entrar en la Armada.

El 20 de julio del mismo año aprueba el examen de ingreso en la Armada y pasa destinado al Hospital de Marina de Cartagena, pero por problemas de créditos presupuestarios del Ministerio, queda suspendido de empleo.

Mientras tanto ingresa en el Colegio de Practicantes de Madrid como socio corresponsal, demostrando su personalidad inquieta.

\section{Practicante de la Armada}

Una vez resuelto el problema económico ministerial, por otra parte, bastante habitual, fue elegido nuevamente aspirante y por R.O. de 26 de octubre de 1912 es nombrado $2^{\circ}$ Practicante, pasando destinado a la Farmacia sucursal del Hospital de Marina de su ciudad.

Compatibilizando su trabajo profesional en la Armada con la institución colegial, se presenta al cargo y es nombrado Presidente del Colegio de Practicantes del Colegio Departamental de Cartagena (191215). También es fundador y propietario de la revista "El Practicante Moderno". Continuando con su desmedido afán corporativo, es elegido Delegado Presidente de la Asociación de Practicantes de la Armada del Departamento Marítimo cartagenero (Martínez 1934).

En 1913, mientras permanecía destinado en la enfermería del Arsenal de Cartagena, a finales de año padece un problema de salud y solicita licencia por enfermedad, en enero de 1914 le conceden dos meses, poniendo como estancia de descanso Madrid y Alicante. Era obligatorio indicar los domicilios, en el caso de haber más de uno, para notificación en caso de necesidad.

De vuelta al Hospital, el 10 de septiembre de 1915 cesa en el destino y embarca en el Contra-Torpedero

\footnotetext{
* De su especialidad.

+ Trámite administrativo para poder desplazarse a otro destino.
}

"Proserpina", tomando el cargo de su “clase”* . En la Armada, según el destino, el profesional podía ir como parte de la dotación o bien como cargo. Ir de cargo significaba ejercer de Jefe de la Enfermería, generalmente por la ausencia de médico $\mathrm{y}$ por ser el practicante más antiguo. En este caso, era el único sanitario a bordo.

Debido a la guerra en Marruecos, el 3 de diciembre de 1916, tras permutar voluntariamente con un compañero, desembarca del "Proserpina” y es pasaportado $^{\dagger}$ a Larache. Destinado al Regimiento Expedicionario de Infantería de Marina, embarca en Cádiz en uno de los buques de transportes, iniciando el trayecto el 11 de enero de 1917.

Pedro José era un hombre de gran personalidad y de recia voluntad, eso quizás le ayudaba a la hora de conseguir destacar sobre los demás. Durante su estancia en Marruecos tuvo un incidente con un superior, que le pudo costar muy caro, sin embargo, supo salir airoso. Sucedió que un $2^{\circ}$ Teniente de su batallón le ordenó explorar a un soldado que se encontraba enfermo en el calabozo. El Brigada ${ }^{\ddagger}$ Martínez Moreno, le contestó que aquel soldado era de otro destino y que lo indicado sería avisar al médico o practicante del $2^{\circ}$ Batallón, al cual pertenecía. El $2^{\circ}$ Teniente, Vicente Serrano Scotto, insistió en su orden sin conseguir que el Suboficial Practicante le obedeciera. Acto seguido lo mandó arrestado a prevención, y Pedro José adujo que por su categoría militar no procedía dicha estancia. En un estado de rabia incontenible, el Oficial desenfundó su sable y le golpeó en el hombro, causándole una pequeña contusión. Aquel incidente trajo consigo partes por escrito de uno contra el otro, que se resolvió con una causa dirigida por el Teniente Coronel Rodríguez García, Juez Instructor. En la misma se condenó al Oficial Serrano por falta de consideración con un inferior, a 8 días de arresto y al Suboficial Martínez por falta de celo profesional, a 4 días ${ }^{\S}$.

\footnotetext{
‡ Categoría militar del Cuerpo de Suboficiales al que pertenecía en esos momentos.

$\S$ Hoja Servicios CGA, Decreto Autoridad Judicial, folio 58
} 
En tiempos bélico, un conflicto de esta naturaleza pudo acabar en un Consejo de Guerra y con un resultado imprevisible, no obstante Martínez Moreno demostró gran valor, defendiendo su integridad moral y profesional por encima del riesgo. Aquel incidente, le hizo ganar prestigio ante sus compañeros y antes sus superiores.

Permanece en zona de guerra los años 1917 y 1918, cesando el 28 de febrero de 1919, siendo destinado a la península.

En su hoja de servicio aparece un escrito informando de su estancia en Larache, donde destaca un párrafo:

...el 8 de octubre de 1918 regresó al campamento de Nador. Durante el tiempo que permaneció destacado en esta última posición, prestó excelentes servicios, reemplazando al médico, permaneciendo constantemente al lado de los numerosos enfermos que a consecuencia de las fiebres palúdicas existían y les era preciso su esmerado cuidado, haciendo un excelente trabajo con tal motivo y consiguiendo, gracias a su celo profesional y amor a los enfermos, reducir el número de éstos y la curación de la mayoría de ellos...

Larache 5 de mayo de 1919

\section{El Jefe del Detall}

\section{Firma ilegible}

Es destacable este informe, donde se alaba el comportamiento profesional y humano y donde se obvia el incidente con el Oficial. Una vez en su domicilio disfruta de los dos meses de licencia reglamentarios, indicando en esta ocasión como probables estancias de descanso, Granada y Cartagena.

El 25 de agosto embarca nuevamente, esta vez en el ContraTorpedero "Cadarso", tomando posesión de su cargo. Su estancia en el Cadarso le costó una "Hoja de castigo". En la misma constaba que estaba rebajado de servicio en su domicilio por el Médico del Arsenal, al alegar no poder andar para acudir al destino. Sin embargo, la noche del día 15, es visto paseando por la calle y por medio de un retén es conducido a bordo. El Jefe del Estado Mayor manda un nuevo reconocimiento y ordena que si está enfermo sea llevado al Hospital y en caso contrario se incorpore a su destino. Reconocido es dado de alta, reincorporado al trabajo:

...el 27 hizo su presentación por ser dado de alta, imponiéndosele diez días de arresto militar.

A bordo en Cartagena el 27 de diciembre de 1919

Firma Cadarso

Segundo Comandante del Buque

\section{Francisco Bernal}

En la misma cuartilla de su Hoja de Servicio donde queda reflejado el incidente anterior, seguidamente, pero con fecha cinco años después, aparece el siguiente texto:

Por Decreto del Excmo. Sr. Capitán General del Departamento de Cartagena de 26 de diciembre del año último, le fue invalidada la nota que antecede.

A bordo en Ferrol 3 de enero de 1925 Méndez Núñez

El Segundo Comandante del Buque

\section{Firma ilegible}

Las notas de castigo en las Hojas de Servicios eran tenidas en cuenta a la hora de los ascensos y para la obtención de menciones honoríficas y medallas militares. Es por ello por lo que Pedro José luchó denodadamente para que, una vez transcurrido el periodo reglamentario de validez, le fuera retirada y no siguiera ensombreciendo sus informes personales.

El 11 de junio de 1921 desembarca por haber cumplido las condiciones de navegación y es destinado al Hospital de Marina de Cartagena, cesa el 18 ocupando plaza en la enfermería del Arsenal de Cartagena, prestando servicio de guardias. El 26 de noviembre finaliza en este destino $\mathrm{y}$ por orden superior es destinado al $3^{\circ}$ Regimiento de Infantería de Marina. La vida del practicante de la Armada en esa época constituía un continuo baile de distintos servicios, siendo los Hospitales de la Marina destinos obligatorios, al considerarlos esenciales para la formación continuada.

En 1922 continúa en el mismo destino y aprovechando este periodo de 
estabilidad, se casa con Rosa del Valle Galarza en Cartagena (Fernández 2019).

El 11 de enero de 1923 cesa por haber ascendido a Practicante $1^{\circ}$ y como "premio" es pasaportado para la sección de Ferrol. Una vez presentado es ubicado en el Servicio de Clínicas del Hospital de Marina de Ferrol, para posteriormente pasar destinado a la Base Naval de Ríos (Vigo). Un año después, continuando con su costumbre de participar de la vida colegial y aprovechando su prestigio y don de gente, se presenta a las elecciones, resultando elegido Presidente del Colegio de Practicantes de Vigo**.

El 20 de agosto de 1924 cesa en la Base por haber sido destinado al Crucero" Méndez Núñez", donde permanece dos años. Dos años después, el 18 de agosto de 1926 desembarca del Crucero por haber cumplido las condiciones reglamentarias para el ascenso, pasando a la Sección del Departamento de Cartagena, haciendo su presentación el 18 de septiembre y siendo como es habitual redireccionado al Hospital de Marina, donde le conceden dos meses de licencia. El 29 de septiembre cesa en el Hospital de Cartagena y regresa nuevamente al Hospital de Ferrol.

En las Hojas de Servicio de los practicantes de la Marina, en el apartado de destinos de barcos, es frecuente observar un mínimo de siete u ocho distintos y muchos más en destinos de tierra, Arsenales, Bases Navales, Hospitales, Enfermerías, etc., pero de menor durabilidad. Cualquier profesional pasaba dos tercios o más de su vida laboral embarcado, sin tenerse en cuenta los años de antigüedad ni la edad de estos.

Pedro José no perdió la ocasión, y de 1926 a 1930, formó parte de la Junta Directiva del Colegio Departamental de Practicantes de Ferrol, siendo nombrado además delegado, para representar al Colegio en las Asambleas Nacionales en Madrid de 1926 y 1930, y de la Asamblea Regional Gallega del último año. Como

\footnotetext{
** Estos Colegios de provincias desaparecerían con la Ley de Colegiación obligatoria y los nuevos Estatutos que establecen un único
}

buen articulista que era, fue nombrado Redactor de "El Practicante Galaico", y durante esos cuatro años de estancia en tierras gallegas, fue Presidente del Casino de Clases de Ferrol. Este último cargo que ejerció en distintas zonas marítimas, le servía como puerta de entrada en la sociedad local, pudiendo desarrollar y destacar por ello de sus habilidades personales.

El 7 de octubre de 1929, cesa en el hospital ferrolano y pasa provisionalmente embarcado al Buque Escuela "Emperador Carlos V", donde al desembarcar el 28 de febrero de 1930, "le dieron las gracias", una forma de felicitar, por celo, pericia $y$ asiduidad, como ayudante en una operación a un oficial sueco. Así reza en su Hoja de Servicio ${ }^{\dagger \dagger}$.

Por esas fechas, la situación política en España pasaba por momentos difíciles. El General Primo de Rivera había dimitido en enero de 1930 y los presidentes nombrados por el Rey Alfonso XIII, Berenguer y Aznar, no pudieron enderezar la situación. Las elecciones de abril de 1931 y sus resultados provocaron que "España se acostara monárquica y se levantara republicana”, en palabras del propio Aznar (Moreno V. 2019). El rey acepta su derrota y se exilia voluntariamente antes de que la situación lo obligara, proclamándose inmediatamente la II República el 14 de abril.

El Gobierno provisional de la República, dentro de lo que se denominó Ley de Azaña, publicó un Decreto de 23 de abril de 1931 (B. O. 91), donde los miembros de las FFAA debían prestar la promesa de adhesión y fidelidad a la República. El texto se ajustaría a la siguiente fórmula:

Prometo por mi honor servir bien y fielmente a la República, obedecer las leyes y defenderla con las armas (Huerta 2016: 475).

Martínez Moreno prometió y firmó dicha adhesión, cuyo incumplimiento le habría provocado el pase forzoso a retirado del Ejército, con los haberes que le hubieran

Colegio en las capitales de provincias. Gaceta de Madrid núm. 363 de 29.12.1929

${ }^{++}$Real Orden 11 de julio 1930. Boletín Oficial no 160 
correspondido. Intención que nunca llegó a plantearse, dado su afinidad ideológica con el régimen establecido.

En septiembre de ese mismo año cesa en el Hospital de Ferrol y es destinado a la Comandancia de Marina de Santa Cruz de Tenerife. A esta nueva etapa de su vida profesional, llega con el ascenso recién conseguido de Primer Practicante de Primera.

En la capital canaria, utilizando sus ya conocidas dotes de líder, es elegido presidente del Colegio de Practicantes de la ciudad y administrador de la Revista "El Practicante Tinerfeño". No satisfecho con estos cargos, es propuesto también como presidente del Casino de Clases "Amistad 12 de enero" de Tenerife. Posteriormente, por los méritos contraídos, sería nombrado Presidente Honorario del Colegio canario. Todo ello a pesar del poco tiempo que permaneció destinado en la citada Comandancia de Marina, ya que el 11 de abril de 1932, recién ascendido nuevamente a Oficial $3^{\circ}$, es destinado a la Enfermería del Arsenal de La Carraca, donde hizo su presentación el 12 de mayo.

Este nuevo destino, por orden del Vicealmirante Jefe de la Base, tendría que compatibilizarlo, ya que interinamente es también comisionado a la Escuela Naval Militar en San Fernando (Cádiz), y por si fuera poco, atendería al Dispensario de la Comandancia de Marina de Cádiz. El famoso Decreto de 23 de abril de 1931, había facilitado la baja de muchos profesionales sanitarios que, por el hecho de no firmar el documento de adhesión a la República, eran pasados a retiro sin detrimento del sueldo que les correspondía. Eso explicaría la falta de practicantes en la Armada y el pluriempleo de estos.

Afortunadamente, el 11 de enero de 1933, cesa del cargo adicional de la Escuela Naval, pero el alivio le dura poco ya que diez días después lo nombraron responsable del cargo de material quirúrgico, que precisamente habían enviado desde la Comandancia de Marina de Santa Cruz de Tenerife, así como del material que había en el Almacén General del Arsenal de La Carraca.

\section{DE CADIZ}

COLEGIO DE PRACTICANTES

La primera noticia de ámbito colegial que conocemos de Martínez Moreno en Cádiz, es en el número 188 de "El Practicante Gaditano” de junio de 1932, donde se le da la bienvenida por su colegiación. Este dato apunta el compromiso que tenía con la institución profesional y su constante implicación con la misma. En las elecciones celebradas en mayo de 1933, resulta elegido Presidente del Colegio de Practicantes de la provincia gaditana.

Nada más comenzar su legislatura, el recientemente nombrado Director de El Practicante Gaditano, Manuel Castellón Sánchez, dimite al obtener una plaza de practicante en Jimena (Cádiz). La Junta directiva conocedora de las cualidades literarias del recién elegido presidente, lo propone para que se haga cargo de la dirección, aceptando sin condiciones, conocedor de la importancia de dirigir un medio de comunicación tan influyente en el plano profesional y social. Pedro José le da un impulso importante al boletín, cambiando y mejorando el formato que en los últimos años había perdido bastante calidad y disminuido el interés general.

Aprovechando esta ocasión, nada más entrar escribió la que sería su carta de presentación como Presidente.

\section{Por MARTINEZ MORENO}

La reciente nombrada Junta Directiva que me honro en presidir, está compuesta en su totalidad por hombres nuevos, con nuevos ideales y nuevas normas para aplicarlos y conseguirlos, que desean ávidamente otro porvenir más lisonjero para la clase a que pertenecen, que para conseguirlo, veían no era el procedimiento más adecuado el que de algún tiempo al presente venían desarrollando los anteriores dirigentes de nuestro Colegio, siendo a nuestro juicio base primordial el cambio absoluto de las normas, por otras de efectos más rápidos, para lo cual en el pasado mes de enero propusimos la imprescindible reforma del vigente Reglamento, por otro eminentemente democrático. No lo creyeron así algunos compañeros de la anterior Directiva, 
iniciando nosotros, como consecuencia la campaña, enfocada a conseguir el cambio radical de táctica, pues la conducta seguida la más adecuada para la pronta anulación total del Colegio como entidad oficial. El dilema era ¡renovarse o morir!, y consciente de nuestro deber, muy a pesar nuestro, nos vimos obligados por las circunstancias a informar a la clase de la provincia de lo que veía sucediendo en el Colegio.

De sobra sabíamos, al poner las cartas boca arriba, nos quedábamos obligados, no solamente indicar la orientación conveniente, sino también ejecutarla, para lo cual expusimos el programa a realizar y acoplamos una candidatura de Junta, comprometiéndonos de antemano (caso de salir elegidos) a cumplir con férrea voluntad nuestros cometidos en los cargos, para demostrar a la clase nuestro aserto...

\section{Martínez Moreno finalizaba:}

Ahora solo nos permitimos pediros una cosa; solo una cosa... ¿COLABORACION, AMPLIA COLABORACION! (El Practicante Gaditano, $n^{\circ} 200$, junio de 1933)

Comenzaba de esta manera una época de cambios y una politización velada de la institución colegial. Hay que contextualizar para entender que era una época donde la sociedad española había sufrido un cambio radical en el sistema político de gobierno y existía una implicación político-social de la población en general, donde los practicantes y los Colegios no eran ajenos a ello. La mayoría de los miembros de la Junta de Gobierno, durante la guerra civil y posteriormente, padecieron situaciones complicadas y en algunos casos dramáticas, incluido el presidente Martínez Moreno, como veremos más adelante.

Siguiendo con su trayectoria militar, el 5 de octubre, sin desatender sus actuales destinos, embarca interinamente en el Crucero "Méndez Núñez", desembarcando mes y medio después, al haber sido relevado.

En la primera semana de enero de 1934, se hace cargo del destino de Auxiliar del Subdirector y encargado del instrumental quirúrgico del Hospital de Cádiz. En marzo, queda disponible forzoso en la Base Naval principal de Cádiz y sin cesar en esa situación, pasa destinado a la Escuela Naval Militar en San Fernando. La interinidad en los destinos y los continuos cambios hacían estragos en las vidas de esos practicantes que tenían que desdoblarse para poder atender todas las actividades que les eran asignadas. Ninguna de estas circunstancias mermaba las pretensiones de Martínez Moreno por compatibilizar las actividades asumidas institucionalmente. No obstante, resulta sorprendente comprender qué le impulsaba a sobrellevarlo, y es que el año que nos ocupa, otra vez, ahora en septiembre, fue cambiado de destino pasando al Arsenal de La Carraca en San Fernando.

Debido quizás a estas agobiantes circunstancias y deseando acercarse a sus familiares, solicitó con carácter interino y voluntario ir destinado al Hospital de Marina de Cartagena, tomando posesión en octubre. Todo ello sin dejar de presidir el Colegio de Practicantes de Cádiz, aunque ya se podía prever su próximo cese.

Termina el ajetreado año 34 y en febrero de 1935 es destinado al Polígono de Tiro Naval Janer en Galicia. Previamente el 27 de enero, había sido sustituido en el Colegio de Practicantes de Cádiz por una nueva Junta de Gobierno, presidida por Julio Cabilla y Alberto, que en su día fuera primer Director de la Revista El Practicante Gaditano. De esta forma, Martínez Moreno, termina su recorrido por tierras gaditanas $\mathrm{y}$ en la institución colegial.

Cansado de tantos cambios y en medio de una situación política complicada, debió sufrir algún problema de salud, que le sirvió para la concesión de dos meses de licencia por enfermo, anticipada por la Superior Autoridad de la Base Naval de Ferrol, como resultado del reconocimiento médico.

En 31 de mayo se presentó al finalizar la licencia concedida, pasando a la situación de disponible forzoso, en Madrid. Este destino, aunque el carácter parece obligado, el hecho de que los dos meses de licencia los pasara en la capital, y diversas circunstancias posteriores, invita a pensar 
que había tenido contactos con altas instancias militares, donde por otra parte se movía con cierta soltura, algo que conociendo su larga trayectoria no debe extrañar.

En junio, toma posesión de su nuevo destino de Oficial $2^{\circ}$ del Centro Estadístico Sanitario, en el Cuartel General de la Armada, además de ocuparse interinamente de atender la asistencia del personal de Marina destinado en Madrid.

Este cargo, como tantos otros, tampoco le duraría mucho y el 14 de octubre cesa en los puestos anteriores, embarcando en el Crucero “Méndez Núñez”. En su hoja de Servicio éste es el último apunte que aparece. A partir de este momento los datos militares obtenidos son de diarios oficiales publicados durante la guerra civil.

En el Diario Oficial del Ministerio de Marina de 23 de abril de 1936, en la sección de recompensas, aparece un listado de marinos otorgándoles la Orden del Mérito Naval con distintivo blanco, entre otros al Oficial tercero D. Pedro José Martínez Moreno, con motivo del quinto advenimiento de la República. Hay que subrayar que fue el único Auxiliar de Sanidad (Practicante) que lo recibió, evidenciando el "compromiso personal" con las autoridades militares, ya que este tipo de condecoraciones eran concedidas por conocimiento expreso del premiado.

En la Gaceta de la República de 2 de diciembre de 1936, en la sección de Negociado de Sanidad, aparece la noticia que el Oficial segundo del Cuerpo de Auxiliares de Sanidad D. Pedro José Martínez Moreno cesa de prestar sus servicios de Asistencia al personal en Madrid y pasa destinado a las órdenes del Jefe de la Base Naval principal de Cartagena.

El 22 de julio de 1937 (D.O. n ${ }^{\circ}$ 233) es destinado al crucero "Libertad", buque insignia de la Flota republicana, relevando a un compañero, José Vidal Espiñeira, que a su vez ocuparía su anterior destino en la Base Naval de Cartagena. Resulta un poco sorprendente esta permuta al que sería su último destino en activo, lo que hace pensar que intuía el trágico final de la fratricida guerra y su complicada situación personal.

Aún encontramos una nueva notificación de su vida laboral activa en el Diario Oficial de 28 de septiembre de 1937, donde es ascendido a Oficial segundo (Teniente), como premio a su lealtad.

El 5 de marzo de 1939, ante los acontecimientos que anunciaban el final de la guerra civil, la Flota republicana se ve obligada a salir del puerto de Cartagena, con el crucero "Libertad" liderándolo y con Pedro José Martínez Moreno en su dotación. Los buques se refugian en Bizerta (Túnez), donde son entregados a las autoridades tunecinas y sus dotaciones internadas en el campo de concentración de Meheri Zebbeus.

Un mes antes de estos trágicos momentos, se publicó en el BOE de 13 de febrero de 1939, la ley de 9 de febrero de 1939 de Responsabilidades Políticas, en la que legitima la sublevación militar y la guerra civil, culpando a quienes por sus actos u omisiones contribuyeron a su desarrollo.

En el Diario Oficial del Ministerio de Marina de 5 de septiembre de 1940, en la Sección de personal, apartado Bajas, aparece el siguiente comunicado:

Por no haber constancia de que haya hecho su presentación a las Autoridades nacionales el personal de los Cuerpos Auxiliares y demás subalternos que a continuación se relaciona, procedente de la zona roja, se dispone cause baja en la Armada, con arreglo a lo preceptuado en la ley de 10 de febrero de 1939, sin perjuicio de que, en el caso de que con posterioridad a la fecha de esta disposición se acredite la presentación de dicho personal a las Autoridades nacionales, se rectifique la misma, señalando a los que le afecte la situación reglamentaria que le corresponda.

En la lista aparecía:

Cuerpo de Auxiliares de Sanidad: Oficial tercero, D. Pedro José Martínez Moreno.

Por tanto, todos los militares profesionales, al finalizar la guerra civil, que no acudieron a presentarse en sus respectivos destinos y se desconocían sus 
Revista científica de la Asociación de Historia y Antropología de los Cuidados (Universidad de Alicante)

paraderos, eran dados de baja mucho beneficio de sus habilidades automáticamente.

interpersonales.

A la baja oficial de la Armada se unió una acusación proveniente del juzgado del TERMC ${ }^{\ddagger \ddagger}$, debido a que estando destinado en el Hospital de San Carlos, el 14 de febrero de 1933 solicitó formar parte de la Logia Igualdad $n^{\circ} 53$ (GCFS-GOE ${ }^{\S \S}$ GLRME $^{* * *}$ ) de San Fernando (Cádiz), a la que pertenecían varios compañeros de su profesión, pero aunque las aplomaciones ${ }^{\dagger \dagger \dagger}$ suscritas por tres miembros del taller lo consideraron en línea recta, es decir, digno de pertenecer a la Orden, su iniciación quedó en suspenso por indicación de la obediencia regional, "mientras se comprueban ciertos extremos”. Aunque lo intentó de nuevo con posterioridad, nunca fue admitido en la Orden.

Es por ello por lo que en 1945 y en su ausencia, el juzgado $n^{\circ} 1$ del TERMC le incoó el sumario 455/1945, para comprobar su pertenencia a la Masonería.

Realizados los trámites del caso, se dictó el 15.10.1945, un auto de sobreseimiento provisional, de acuerdo con el párrafo primero del artículo 641 de la LEC ++ , puesto que no resultaba debidamente justificada la "perpetración del delito", y se procedió a archivar las actuaciones sin ulterior curso y "hasta nuevos méritos”. (De Paz, 2004:276)

Martínez Moreno, desconocemos si ajeno a todo lo anterior, vivió en Túnez hasta el 14 de abril de 1957, en que falleció y fue enterrado en El Borgel, en la sección F, Cuadrado I, tumba $\mathrm{n}^{\circ}$ 240. (Fernández 2018).

\section{CONCLUSIONES}

Pedro José Martínez Moreno, era un Practicantes de la Armada que destacaba sobremanera en el ámbito profesional y en sus cualidades particulares, obteniendo

\footnotetext{
¥‡ Tribunal Especial para la represión de la Masonería y el Comunismo, creado por Ley de 01.03.1940

$\S \S$ Gran Consejo Federal Simbólico del Gran

Oriente Español

*** Gran Logia Regional del Mediodía de España
}

Las habilidades personales nos ayudan a tener una comunicación más beneficiosa con los demás, a expresar mejor lo que decimos y a entender lo que se nos quiere comunicar. Las habilidades interpersonales forman un conjunto de comportamientos y hábitos necesarios para garantizar una adecuada interacción, mejorar las relaciones personales $y$ alcanzar los objetivos de la comunicación. $\S \S \S$

Es más que posible que Pedro José, sea único en la historia de la representatividad institucional colegial, tanto en las distintas presidencias como en el resto de las responsabilidades.

En el ámbito militar tampoco pasó desapercibido como hemos podido apreciar, siendo condecorado en distintas ocasiones, a destacar la Medalla de Marruecos, la Medalla de Homenaje a SS MM (Sus Majestades Alfonso XII y Victoria Eugenia), la Cruz de Plata del Mérito Naval con distintivo rojo y por último la Orden del Mérito Naval con distintivo blanco, con motivo del quinto advenimiento de la República.

Todo lo anterior no le sirvió de nada a Pedro José y se convirtió en una víctima más del mayor fracaso de la convivencia ciudadana, que supuso el enfrentamiento armado entre los habitantes de un mismo pueblo, de una misma nación.

Actualmente ignoramos todo lo relacionado con su vida en Túnez. Conociendo al personaje, cuesta trabajo creer que su vida en tierras del norte de África pasara inadvertida. Seguiremos investigando.

\section{FUENTES Y BIBLIOGRAFÍA}

\footnotetext{
${ }^{++\dagger}$ Entrevistas para ingresar en la Masonería

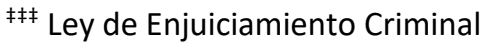

$\$ \S$ https://www.universidadviu.es/las-

habilidades-interpersonales-en-el-

desarrollo-profesional/
} 
escritas y orales

Archivo Central del Cuartel General de la Armada. Madrid. Hoja de Servicios.

Archivo Colegio de Enfermería de Cádiz. Expediente colegial.

Archivo General de la Marina Álvaro de Bazán. Viso del Marqués, Ciudad Real. Expediente Militar.

Diario Oficial del Ministerio de Marina. Madrid, 5 de septiembre de 1940.

El Practicante Gaditano. Boletín del Colegio de Practicantes de Cádiz (1933). Junio, No 200.

Fernández Díaz, V. (2018) Catedrática jubilada de francés en la Escuela de Idiomas, Máster de Historia en la Universitat de València. Documentación personal.

\section{BIBLIOGRAFÍA}

Cano Leal M. y García González, M. (2018). Proceso de investigación en el reconocimiento a las Presidentas del Colegio de Auxiliares Sanitarios de Cádiz, Secciones de Matronas y Enfermeras (1952-1977).

Enfermería Gaditana. Revista digital del Excmo. Colegio de Enfermería de Cádiz. Recuperado de https://enfermeriagaditana.coecadiz.com/pr oceso-de-investigacion-en-el-reconocimiento-alas-presidentas-del-colegio-de-auxiliaressanitarios-de-cadiz-secciones-de-matronas-yenfermeras-1952-1977/

Cano Leal, M. (2018). Manuel Quignon Lubrano. Enfermería Gaditana. Revista digital del Excmo. Colegio de Enfermería de Cádiz. Recuperado de https://enfermeriagaditana.coecadiz.com/ma nuel-quignon-lubrano/

Clavijo y Clavijo, S. (1925). Historia del Cuerpo de Sanidad de la Armada (Génesis; perspectiva de siglos; ruta de libertad; sus celebridades). Tipografía de Fernando Espín Peña.

De Paz Sánchez, M. (2004) Militares Masones de España. Diccionario biográfico del Siglo $X X$. Alzira-Valencia $<$..Centro Francisco Tomás y Valiente UNED.

Fernández Fernández, M.L., García Martínez, A.C. y García Martínez, M.J. (2015) Un siglo cuidando a la sociedad. Centenario del reconocimiento oficial de la Enfermería en España. Santander: Colegio de Enfermería de Cantabria.

García González, M. y Cano Leal, M. (2019) Julio Cabilla Alberto, practicante y periodista de Cádiz (1897-1955). Cuadernos de Investigación de Fondos del Archivo UCA. Recuperado de https://revistas.uca.es/index.php/cifa/article/ view/4966/5351

Gracia Rivas, M. (2006). La sanidad naval española. Cuadernos de Historia Moderna. Anejos, 5, 579-3826.

González Yanes, J. (2014). Historia de la Enfermería en la Defensa. Ejército de Tierra. Regulación normativa y marco jurídico de funciones profesionales. Recuperado de http://aniortenic.net/archivos/trabaj_historia_enfermeria _defensa_ejercito_tierra.pdf

Huerta Barajas, J. A. (2016). Gobierno y Administración Militar en el II República Española (14 de abril de 1931/18 de julio de 1936). Madrid: BOE.

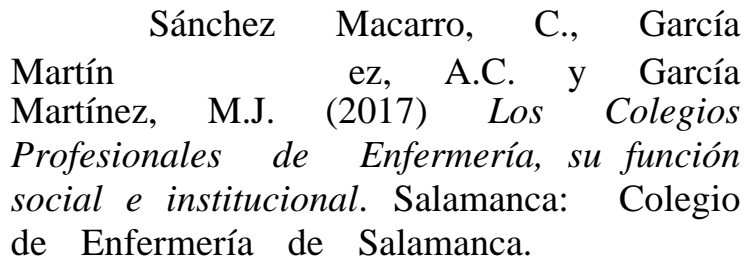
de Enfermería de Salamanca. 